\title{
A Novel PLP1 Mutation Further Expands the Clinical Heterogeneity at the Locus
}

\author{
Collette Kathleen Hand, Geneviève Bernard, Marie-Pierre Dubé, \\ Michael Israel Shevell, Guy Armand Rouleau
}

\begin{abstract}
Objectives: To characterize at clinical and molecular levels a family presenting with X-linked recessive Hereditary Spastic Paraplegia (HSP). Background: HSPs are a large group of genetically heterogeneous neurodegenerative disorders characterized by progressive upper motor neuron signs. Mutations in the proteolipid protein (PLP1) gene have been identified in families linked to the SPG2 locus on chromosome Xq22. However, Pelizaeus-Merzbacher disease (PMD) is also an X-linked recessive neurological disorder caused by PLP1 mutations. Methods: The SPG2 locus was investigated by linkage analysis in the family. The PLP1 gene was screened by sequencing. We present findings in a large French-Canadian family with an X-linked recessive HSP. The proband presented early with developmental delay and developed progressive spastic paraplegia. He has been wheelchair-bound since the age of three years. At the latest follow-up, he was 20 years-old and had severe spasticity predominantly affecting the lower extremities, moderate cerebellar dysfunction, and optic atrophy. Results: Linkage to SPG2 was established and a G to A mutation (M1R) in the initiation codon of the PLPI gene was identified, likely resulting in the complete absence of proteolipid protein. Conclusions: We report a new PLPI gene mutation in a patient with a clinical phenotype consistent with a PLP1 null syndrome.
\end{abstract}

RÉSUMÉ: Une nouvelle mutation dans le gène PLP1 accroît l'hétérogénéité clinique de ce locus. Objectif : Le but de l'étude était de caractériser au niveau clinique et moléculaire une famille atteinte de paraplégie spastique héréditaire (PSH). Contexte : Les PSH constituent un groupe de maladies neurodégénératives hétérogènes au point de vue génétique qui se caractérisent par des signes d'atteinte progressive du neurone moteur supérieur. Des mutations du gène de la protéine protéolipide (PLP1) ont été identifiées dans des familles chez qui la maladie était liée au locus du gène de la paraplégie spastique liée au chromosome X, SPG2, situé en Xq22. Cependant, la maladie de Pelizaeus-Merzbacher (MPM) est également une maladie neurologique liée au chromosome X et causée par des mutations du gène PLP1. Méthode : Nous avons examiné le locus du gène SPG2 par analyse de liaison dans cette famille. Le gène de la PLP1 a été séquencé. Nous présentons les observations faites dans une grande famille canadienne-française atteinte de PSH liée au chromosome X. Le cas index a consulté en bas âge parce qu'il présentait un retard de développement et une paraplégie spastique progressive. Il est en fauteuil roulant depuis l'âge de trois ans. Au moment du dernier examen de suivi, il avait 20 ans et présentait une spasticité sévère touchant surtout les membres inférieurs, une dysfonction cérébelleuse modérée et une atrophie optique. Résultats : Nous avons constaté que la maladie était liée au locus $\mathrm{SPG} 2$ et identifié une mutation $\mathrm{G} \rightarrow \mathrm{A}(\mathrm{M} 1 \mathrm{R})$ dans le codon d'initiation du gène de PLP1, ce qui donne vraisemblablement lieu à une absence complète de la protéine protéolipide. Conclusions : Nous rapportons une nouvelle mutation du gène de la PLP1 chez un patient présentant un phénotype clinique compatible avec une absence totale de la protéine.

Can J Neurol Sci. 2012; 39: 220-224

Hereditary spastic paraplegias (HSP) are a large group of clinically and genetically heterogeneous neurodegenerative disorders characterized by progressive upper motor neuron dysfunction involving preferentially the lower extremities leading to progressive gait spasticity. Hereditary spastic paraplegias are classified clinically as complicated or uncomplicated. The term "uncomplicated" or "pure" HSP is used when spastic paraparesis, with its associated upper motor neuron signs or symptoms (e.g. spastic bladder), are the only features. The term "complicated" or "complex" is used when additional clinical features are present, such as peripheral neuropathy, amyotrophy, sensorineural hearing loss, optic atrophy, seizures, mental retardation, dementia, and extrapyramidal signs. Hereditary spastic paraplegias are also classified according to their mode of inheritance: autosomal dominant, autosomal recessive and X-linked. To date, over 40 genetic loci and 17 genes have been identified. Four X-linked HSP loci have been reported and two causative genes have been identified. SPG1 (MIM 303350) is caused by mutation of the LICAM gene on chromosome Xq28 ${ }^{1}$. SPG2 (MIM 312920) on chromosome Xq22 results from mutation of the myelin

From the Department of Pathology (CKH), University College Cork, Ireland; Department of Neurology and Neurosurgery (GB, MIS), Department of Pediatrics, Montreal Children's Hospital, McGill University Health Centre; Research Centre of the Montreal Heart Institute (MPD); Department of Medicine, Center of Excellence in

Neuromics (GAR), Université de Montréal, Montreal, Quebec, Canada. Received July 15, 2011. Final Revisions Submitted October 3, 2011. Correspondence to: Guy A. Rouleau, Center of Excellence in Neuromics of Université de Montréal, CHUM Research Center, J.A. de Sève Pavilion, Room Y-3633, 1560, Sherbrooke Street East, Montreal, QC, H2L 4M1, Canada. 
proteolipid protein $(P L P 1)$ gene $^{2}$. No genetic defect has yet been identified in the remaining $\mathrm{X}$ chromosome loci SPG16 (MIM 300266) $)^{3,4}$ and SPG34 (MIM 300750).

Pelizaeus-Merzbacher disease (PMD) is an X-linked recessive hypomyelinating leukodystrophy caused by mutations of the proteolipid protein gene $(P L P 1)$ and is thus allelic to $\mathrm{SPG}^{6}$. Pelizaeus-Merzbacher disease typically presents in infancy or early childhood with developmental regression, nystagmus and hypotonia progressing to spastic quadraparesis ${ }^{7}$. The most common mutation type is a gene duplication which results in a relatively mild form of the disease ${ }^{8,9}$. Interestingly, null mutations were reported in families with a mild form of the disease $\mathrm{e}^{10-12}$, while patients with point mutations present the most severe phenotypes ${ }^{7}$.

Three subtypes of PMD have been described and are differentiated by their age of onset and severity ${ }^{13-15}$. Connatal PMD has the most severe phenotype with onset in the neonatal period; these patients never achieve ambulation. Classic PMD has intermediate severity with onset in infancy or early childhood. These children eventually achieve ambulation with assistance but motor regression during childhood or adolescence results in the loss of ambulation skills. The least severe form of PMD is the PLP1 null syndrome which presents before five years of age and progresses more slowly. Children with this form do not develop nystagmus but do develop a peripheral neuropathy. Despite a mild spastic quadraparesis, they achieve independent ambulation, but with some degree of ataxia.

\section{PLP}

The gene that encodes the myelin proteolipid protein ( $P L P 1)$ is alternatively spliced yielding two transmembrane proteins PLP and DM20 ${ }^{16}$. These proteins are among the most abundant in the central nervous system (CNS) constituting approximately $50 \%$ of the total myelin proteins. Both are transmembrane proteins and it is thought that PLP is probably involved in myelin compaction. Mutations of the PLPl gene lead to dysfunction and death of the oligodendrocytes.

PLPl gene mutations have been described in both PMD and $\mathrm{X}$-HSP families. To date, 118 mutations have been reported (Human Gene Mutation Database) and include gene duplication, deletion, missense and splicing mutations. Mutations are usually unique to a single family ${ }^{7}$.

\section{SubJECTS AND METHODS}

\section{Patients}

This French-Canadian family has had affected males in the last two generations. Inheritance of the disease is X-linked recessive as evidenced by the transmission of the disease through the unaffected maternal line. Family members were recruited and assessed by experienced neurologists. All patients provided informed consent according to the criteria of the Institutional Review Board of McGill University, Montreal, Quebec.

The proband is a male who was first seen in neurology at the age of ten months for gross motor difficulties. His family history is significant for several family members, all males, affected by HSP (Figure 1). The patient's perinatal history was

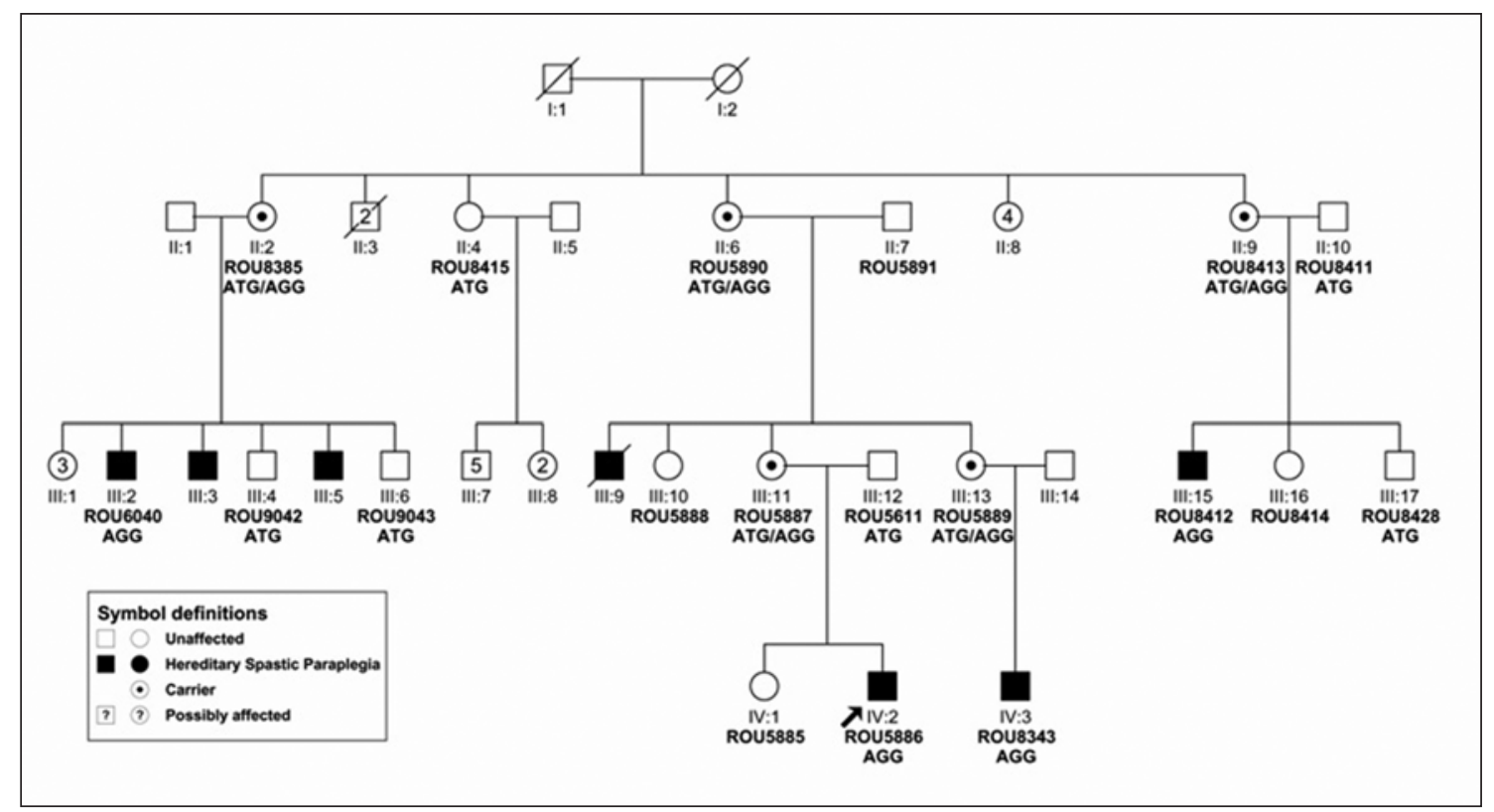

Figure 1: Pedigree of X-HSP family indicating affected individuals (solid symbols). The proband is indicated by an arrow. The PLP1 exon 1 mutation status is indicated for the individuals analyzed. To preserve confidentiality the symbols and/or mutation status of a number of individuals have been omitted from this pedigree. In the second generation there are four additional females who do not have affected children and so their mutation status has not been disclosed. 

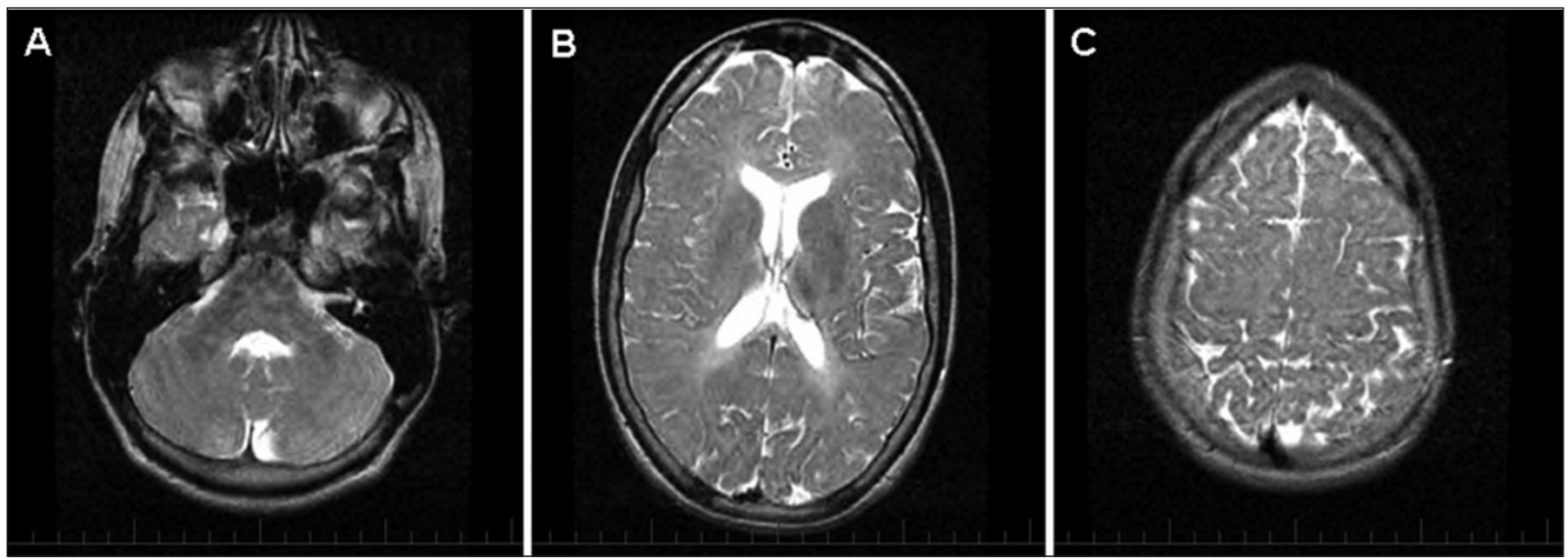

Figure 2: MRI performed at the age of 12 years. A) Axial MRI, T2-weighted: normal white matter signal in the brainstem and cerebellum. B) Axial MRI, T2-weighted: mild hyperintensities in the periventricular and deep white matter regions. C) Axial MRI, T2-weighted: normal white matter signal in the cerebral hemispheres besides the periventricular regions.

unremarkable. He presented in the first year of life with gross motor delay and was found to have spasticity of the lower extremities, hyperreflexia and bilateral Babinskis, along with axial hypotonia. He was diagnosed with probable X-linked recessive HSP. In the second year of life, he developed intermittent vertical nystagmus of the right eye; which disappeared on subsequent neuro-ophthalmological evaluations. He never achieved independent walking. Over the years, the spasticity in his lower extremities worsened and he developed upper motor neuron signs in the upper extremities, a hyperreflexic bladder, dysarthria, optic atrophy and scoliosis, for which he was operated on at the age of 16 years. At the latest neurological follow-up, at 20 years-of-age, the patient had mild cognitive dysfunction, significant dysarthria, restriction of extraocular movements, optic atrophy, slow rapid alternating movements, with spasticity and hyperreflexia involving the lower extremities much more than upper extremities. Extensive investigations were performed throughout the years. Of interest, a magnetic resonance imaging (MRI) of the brain was performed at the age of 12 years and showed hyperintense signal of the periventricular and deep white matter, better seen on T2weighted imaging and fluid-attenuated inversion recovery (FLAIR) (Figure 2). His spinal MRI was normal. Electromyogram and nerve conduction studies showed a mild sensorimotor demyelinating polyneuropathy with decreased nerve conduction velocities.

\section{Molecular Analysis}

Blood was taken from informed, consenting individuals and DNA extracted following standard protocols. Linkage analysis was performed using microsatellite markers DXS990, DSX8020, DSX8089 and DXS8112 from the SPG2 locus. The model used for analysis was an X-linked recessive trait, with $75 \%$ penetrance, $0 \%$ phenocopy, and $0.01 \%$ allele frequency. PCRamplified fragments of exon one of the PLPI gene were sequenced on both strands (forward primer:
AGCCGGCTACAATTGGAGTCAGA, reverse primer: TAACTCCTTCTCCGCTGTACTAA) using a thermosequenase ${ }^{33} \mathrm{P}$ cycle sequencing kit (United States Biochemical, Cleveland, $\mathrm{OH})$. Sequences were resolved on $6 \%$ polyacrylamide gels and detected by autoradiography.

\section{RESUlts}

Linkage was established to the SPG2 locus with a maximum lod score of 4.24 at theta $=0.0$ for the microsatellite DXS8020. Sequencing analysis of individuals Rou5886 and Rou5611 from this family (Figure 1) revealed a novel PLPl mutation (ATG$>$ AGG shift) (Figure 3). Analysis of the DNA from all available family members confirmed the presence of this M1R mutation in all affected individuals. The mother of each affected boy also carried the mutation which was not detected in any unaffected individuals (Figure 1).

\section{Discussion}

Mutations in the PLP1 gene are reported to cause the allelic disorders of PMD and X-HSP (SPG2). Duplication of the gene is the most common cause of PMD (12) and results in the phenotype known as classical PMD. Missense mutations in PLPl cause the most severe subtype of PMD (connatal). Most of the SPG2 mutations reported are missense mutations. The majority of $P L P 1$ point mutations cause a more severe phenotype than null mutations suggesting that the aberrant protein has a deleterious effect.

To date, two mutations have been reported in the PLPl initiator codon, Met1Ile and Met1Thr ${ }^{9,10}$, both causing a mild PMD phenotype similar to the phenotype caused by $P L P l$ gene deletion $^{11}$. In our family, we report a similar mutation (Met1 Arg), expected to result in the total absence of PLP and DM20 proteins.

Our patient's clinical features and imaging findings are consistent with a clinical phenotype of PLP1 null syndrome but 


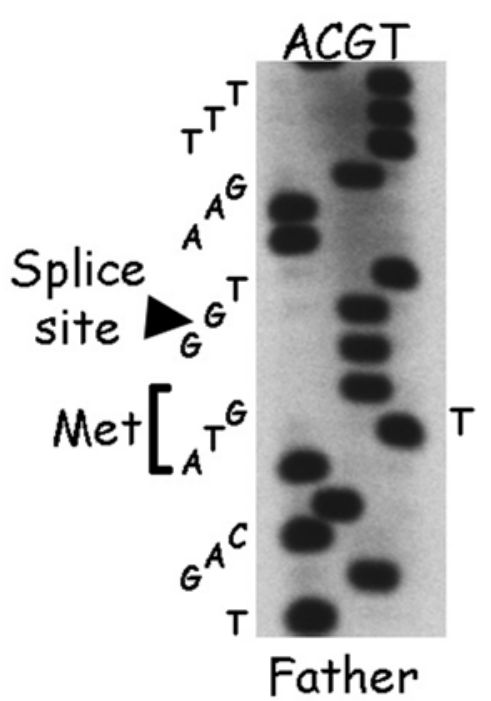

Rou8411

(unaffected)

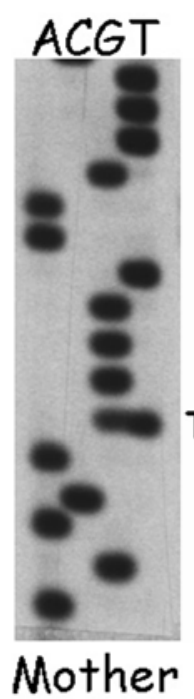

Rou8413

(carrier)

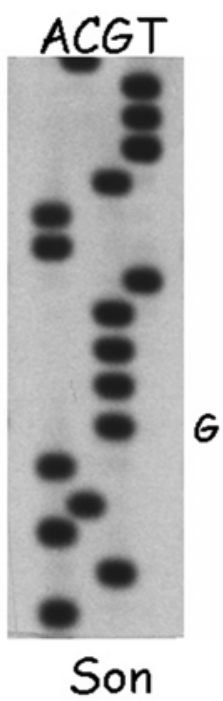

Rou8412

(affected)

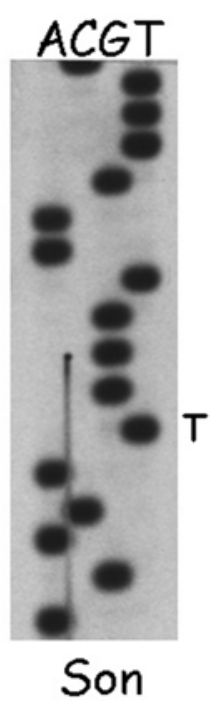

Rou8428

(unaffected)

Figure 3: Sequence of PLP1 exon 1 in the region of interest. The father displays the normal sequence; the mother who is a carrier of the mutated gene is a MIR heterozygote and the site of the $T->G$ shift is indicated. Their affected son carries the mutated initiator codon (AGG) while their unaffected son has a normal (ATG) copy of the codon. Met indicates the methionine start codon.

presents some clinical findings suggestive of a severe complicated HSP, such as the severe spasticity in the lower extremities, the hyperreflexic bladder and the absence of significant cognitive involvement. The PLP1 null syndrome and the complicated form of HSP-2 share several characteristics, such as age of onset, spasticity, and cerebellar involvement. However, the presence of nystagmus early in the course, the severity of spasticity as well as the MRI result are more consistent with a severe form of complicated HSP ${ }^{17}$. The other clinical findings are more typical of the PLP1 null syndrome; the patient's motor milestones were delayed as early as the first year of life $\mathrm{e}^{14}$ and the presence of axial hypotonia early $\mathrm{on}^{2}$. The patient nerve conduction studies and MRI results are also consistent with this diagnosis ${ }^{18,19}$. It is interesting to note that the only PLP1-related disease where ambulation is never achieved is the connatal form, which this patient certainly did not have. The age of death of the patient's uncle (17 years) is somewhat atypical for both diseases; death at that early age is typically reported only with the most severe form of PMD (connatal).

We believe that our patient raises the important question of whether PMD and SPG2 are two different allelic diseases or one disease with variable severity. The latter is probably more likely and our patient, presenting typical features of both PMD and SPG2 would be in the middle of the spectrum, both in terms of his clinical manifestations and in terms of his imaging findings. The identification of the causative mutation in this family provides further evidence of the significant overlap between the two disorders and further evidence for consideration as a single entity with a spectrum of phenotypes.

\section{ACKNOWLEDGEMENTS}

The authors thank the family members for their cooperation. G.A.R. is supported by the Canadian Institutes of Health Research. G.B. is supported by fellowship grants from the Fonds de la Recherche en Santé Québec (FRSQ) and Réseau de Médecine Génétique Appliquée (RMGA) Québec.

Authors Collette Kathleen Hand and Geneviève Bernard contributed equally to this work.

\section{REFERENCES}

1. Jouet M, Rosenthal A, Armstrong G, et al. X-linked spastic paraplegia (SPG1), MASA syndrome and X-linked hydrocephalus result from mutations in the L1 gene. Nat Genet. 1994;7(3):402-7.

2. Saugier-Veber P, Munnich A, Bonneau D, et al. X-linked spastic paraplegia and Pelizaeus-Merzbacher disease are allelic disorders at the proteolipid protein locus. Nat Genet. 1994;6(3): 257-62.

3. Steinmüller R, Lantigua-Cruz A, Garcia-Garcia R, Kostrzewa M, Steinberger D, Müller U. Evidence of a third locus in X-linked recessive spastic paraplegia. Hum Genet. 1997;100(2):287-9.

4. Tamagaki A, Shima M, Tomita R, et al. Segregation of a pure form of spastic paraplegia and NOR insertion into Xq11.2. Am J Med Genet. 2000;94(1):5-8. 
5. Macedo-Souza LI, Kok F, Santos S, et al. Reevaluation of a large family defines a new locus for X-linked recessive pure spastic paraplegia (SPG34) on chromosome Xq25. Neurogenetics. 2008;9(3):225-6.

6. Hudson LD, Puckett C, Berndt J, Chan J, Gencic S. Mutation of the proteolipid protein gene PLP in a human X chromosome-linked myelin disorder. Proc Natl Acad Sci USA. 1989;86(20):8128-31.

7. Inoue K. PLP1-related inherited dysmyelinating disorders: Pelizaeus-Merzbacher disease and spastic paraplegia type 2 . Neurogenetics. 2005;6(1):1-16.

8. Inoue $\mathrm{K}$, Osaka $\mathrm{H}$, Imaizumi $\mathrm{K}$, et al. Proteolipid protein gene duplications causing Pelizaeus-Merzbacher disease: molecular mechanism and phenotypic manifestations. Ann Neurol. 1999; 45(5):624-32.

9. Sistermans EA, de Wijs IJ, de Coo RF, Smit LM, Menko FH, van Oost BA. A (G-to-A) mutation in the initiation codon of the proteolipid protein gene causing a relatively mild form of Pelizaeus-Merzbacher disease in a Dutch family. Hum Genet. 1996;97(3):337-9.

10. Mimault C, Giraud G, Courtois V, et al. Proteolipoprotein gene analysis in 82 patients with sporadic Pelizaeus-Merzbacher Disease: duplications, the major cause of the disease, originate more frequently in male germ cells, but point mutations do not. The Clinical European Network on Brain Dysmyelinating Disease. Am J Hum Genet. 1999;65(2):360-9.

11. Raskind WH, Williams CA, Hudson LD, Bird TD. Complete deletion of the proteolipid protein gene (PLP) in a family with Xlinked Pelizaeus-Merzbacher disease. Am J Hum Genet. $1991 ; 49(6): 1355-60$
12. Sistermans EA, de Coo RF, De Wijs IJ, Van Oost BA. Duplication of the proteolipid protein gene is the major cause of PelizaeusMerzbacher disease. Neurology. 1998;50(6):1749-54.

13. Boulloche J, Aicardi J. Pelizaeus-Merzbacher disease: clinical and nosological study. J Child Neurol. 1986;1(3):233-9.

14. Cailloux F, Gauthier-Barichard F, Mimault C, et al. Genotypephenotype correlation in inherited brain myelination defects due to proteolipid protein gene mutations. Clinical European Network on Brain Dysmyelinating Disease. Eur J Hum Genet. 2000;8(11):837-45.

15. Hodes M, Pratt V, Dlouhy S. Genetics of Pelizaeus-Merzbacher disease. Dev Neurosci. 1993;15(6):383-94.

16. Nave K, Lai C, Bloom F, Milner R. Splice site selection in the proteolipid protein (PLP) gene transcript and primary structure of the DM-20 protein of central nervous system myelin. Proc Natl Acad Sci USA. 1987;84(16):5665-9.

17. Bonneau D, Rozet JM, Bulteau C, et al. X linked spastic paraplegia (SPG2): clinical heterogeneity at a single gene locus. J Med Genet. 1993;30(5):381-4.

18. Garbern JY, Cambi F, Tang X-M, et al. Proteolipid protein is necessary in peripheral as well as central myelin. Neuron. 1997; 19(1):205-18

19. Garbern JY, Yool DA, Moore GJ, et al. Patients lacking the major CNS myelin protein, proteolipid protein 1, develop lengthdependent axonal degeneration in the absence of demyelination and inflammation. Brain. 2002;125(3):551-61. 